\title{
Retraction Note to: Investigating the effects of drought on the environment in northwestern province of Iran, Ardabil, using combined indices, Iran
}

\author{
Behrouz Sobhani $^{1}$ - Leyla Jafarzadehaliabad ${ }^{1} \cdot$ Vahid Safarian Zengir $^{1}$
}

Published online: 19 August 2021

(c) Springer Nature Switzerland AG 2021

\section{Retraction to: Modeling Earth Systems and Environment (2020) 6:983-993 https://doi.org/10.1007/s40808-020-00733-w}

The Editors-in-Chief and Publisher have retracted this article (Sobhani et al. 2020) because the validity of the content of this article cannot be verified. An investigation by the Publisher found evidence suggestive of attempts to subvert the peer review and publication system.

Behrouz Sobhani, Leyla Jafarzadehaliabad and Vahid Safarian Zengir do not agree with this retraction.
The original article can be found online at https://doi.org/10.1007/ s40808-020-00733-w.

Vahid Safarian Zengir

safariyan.vahid@gmail.com

1 Department of Physical Geography, Climatology, Faculty of Literature and Humanities, University of Mohaghegh Ardabili, Ardabil, Iran

\section{Reference}

Sobhani B, Jafarzadehaliabad L, Zengir VS (2020) Investigating the effects of drought on the environment in northwestern province of Iran, Ardabil, using combined indices, Iran. Model Earth Syst Environ 6:983-993. https://doi.org/10.1007/s40808-020-00733-w

Publisher's Note Springer Nature remains neutral with regard to jurisdictional claims in published maps and institutional affiliations. 